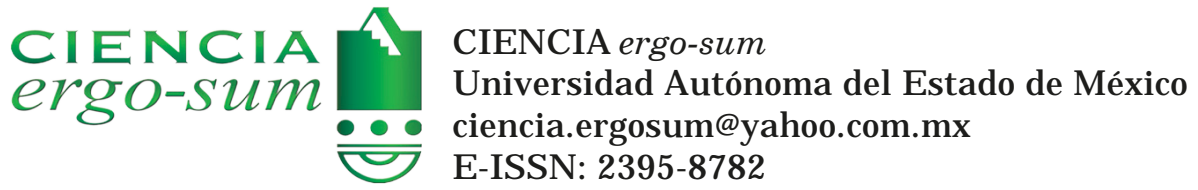

\title{
Autor, exotopía y alteridad en la construcción de identidad nacional desde el cine indigenista en México: Chilam Balam (1955) de Íñigo de Martino
}

León O'F arrill, I srael

Autor, exotopía y alteridad en la construcción de identidad nacional desde el cine indigenista en México:

Chilam Balam (1955) de Íñigo de Martino

CIENCIA ergo-sum, vol. 29, núm. 1, marzo-junio 2022 | e149

Ciencias Humanas y de la Conducta

Universidad Autónoma del Estado de México, México

Esta obra está bajo una Licencia Creative Commons Atribución-NoComercial-SinDerivar 4.0 Internacional.

$$
\text { cc) }(\$
$$

León O'F arrill, I. (2022). Autor, exotopía y alteridad en la construcción de identidad nacional desde el cine indigenista en México: Chilam Balam (1955) de Í ñigo de Martino. CI E N CIA ergo-sum, 29(1). https://doi.org/10.30878/ces.v29n1a5 


\title{
Autor, exotopía y alteridad en la construcción de identidad nacional desde el cine indigenista en México: Chilam Balam (1955) de Íñigo de Martino
}

\section{Author, exothopie and otherness in the construction of national identity from the indigenist cinema in Mexico: Chilam Balam (1955) by Ínigo de Martino}

\author{
Israel León O'Farrill \\ Benemérita Universidad Autónoma de Puebla, México \\ israelleonof@gmail.com
}

Recepción: 30 de junio de 2020

Aprobación: 25 de septiembre de 2020

(D) http://orcid.org/0000-0002-1204-6490

\begin{abstract}
RESUMEN
Se analiza, desde el dialogismo propuesto por Bajtín (autor, exotopía y alteridad), la forma como el cine de corte indigenista colaboró en la construcción de la identidad nacional a partir del nacionalismo mexicano en detrimento de la imagen y el concepto de lo indígena en nuestro país. Para modelar este análisis, se aborda la película Chilam Balam (1955) de Î́nigo de Martino. Se parte de que, una vez concluida la etapa armada de la Revolución mexicana, se emprendió la construcción de una identidad nacional para generar cohesión en torno al proyecto de nación. Actividades como la educación, el arte y los medios de comunicación fueron preponderantes para diseminar los discursos de lo nacional a todos los niveles de la sociedad mexicana.
\end{abstract}

Palabras clave: identidad, Bajtín, cine, indigenismo, Chilam Balam.

\begin{abstract}
The way in which indigenous cinema collaborated in the construction of national identity based on Mexican nationalism to the detriment of image and concept of the indigenous in our country from the dialogism proposed by Bajtín (author, exotopy and alterity) is analyzed. To model this analysis, the film Chilam Balam (1955) by Î́nigo de Martino is approached. Once the armed phase of the Mexican Revolution was over, the construction of a national identity was undertaken to generate cohesion around the national project. Activities such as education, art and the media were preponderant in disseminating national discourses to all levels of Mexican society.
\end{abstract}

KEYwORDs: Identity, Bakhtín, cinema, indigenism, Chilam Balam.

\section{INTRODUCCIÓN}

El fin de la etapa armada de la Revolución mexicana trajo como consecuencia que nuevos grupos se integraran a la toma de decisiones, con otros discursos y perspectivas. El nacionalismo mexicano, como herramienta utilizada por el Estado para generar cohesión de la sociedad mexicana en torno al proyecto nacional propuesto por estos grupos, se valió de múltiples vías para hacer llegar a la población los principales elementos que estructurarían una identidad nacional. Esto se ve en la formación y consolidación de un sistema educativo nacional desde la Secretaría de Estado constituida para tal efecto y encabezada en sus inicios por José Vasconcelos, proyecto que no sólo iba encaminado a la educación de todos los mexicanos en los conocimientos "universales" producidos por la humanidad y sancionados por Occidente, sino que también buscaba ubicar a México en el concierto de otros Estados nacionales, con historias e identidades aparentemente bien establecidas a través de discursos centrados en la Modernidad, la evolución del ser humano y las sociedades y el desarrollo político, económico y social del orbe en su conjunto. 
Para ello, a la par de la inserción del país en los ámbitos políticos y económicos internacionales, había que constituir lo nacional desde esas mismas dinámicas, pero también consolidando la idea de México que se venía construyendo desde el siglo XIX, posterior a la revolución de Independencia y que tantos conflictos había generado entre visiones político-económicas encontradas. Al parecer, después de la eliminación sistemática de los líderes de las diversas facciones detrás del movimiento revolucionario y de una aparente consolidación de la institucionalidad burocrática y política en el Estado, se podía ya definir aquello que se entendía por "México" y cómo debía ser transmitido. El resultado fue la construcción de una imagen de la nación sustentada en numerosos discursos, muchos de ellos terriblemente contradictorios, pero donde el mestizaje fue el centro toral de la discusión.

El llamado fue a numerosos creadores, intelectuales, políticos y líderes sociales para integrarse a la elaboración de los variados discursos encaminados al desarrollo de esa identidad nacional sustentada en la conjunción de dos grandes abstracciones: la cultura prehispánica y la europea, sobre todo la española, ambas fusionadas por el drama de la Conquista, lo que dio como resultado, después de 300 años de la Colonia y un siglo de formación independiente a la joven, pero largamente proyectada nación mexicana. En este tenor, se integrarán a esta labor pintores como los muralistas Rivera, Orozco y Siqueiros, escritores como Azuela, Magdaleno, Abreu, Rafael F. Muñoz, cineastas como Emilio el Indio Fernández, Fernando de Fuentes, Ismael Rodríguez, Juan Bustillo Oro, entre otros.

En este artículo, analizaré el fenómeno de la construcción de identidad nacional a partir del examen de una de esas expresiones, el cine indigenista, en concreto de la película Chilam Balam (1955), dirigida por Íñigo de Martino. Aprovecharé los conceptos de autor-héroe, alteridad y exotopia del ruso Mijaíl Bajtín, aspectos que me permitirán explicar la forma en que el nacionalismo mexicano y sus principales actores construyeron una visión del otro desde preceptos occidentales con el objeto de producir una identidad nacional sustentada en el pasado prehispánico interpretado a mediados del siglo XX desde el cine.

\section{Autor, EXOTOPÍA y ALteridad}

La filosofía de Bajtín - denominada filosofía del acto por Tatiana Bubnova, destacada traductora y estudiosa del filósofo ruso, en su prólogo al libro Yo también soy (Fragmentos sobre el otro) (2015: 17)-, la cual está encaminada a la comprensión del ser en una clave dialógica, establece que nuestra construcción como seres se encuentra supeditada sin duda a nuestra convivencia con otros. "El dialogismo resulta ser, así, un punto de vista capaz de ofrecer la posibilidad de ver y comprender todos los demás puntos de vista existentes como un evento unitario: no una abstracción del 'ser', sino un mero acontecer, su devenir conjunto con el otro" (Bubnova en Bajtín, 2015: 17). En efecto, implica no precisamente la existencia como algo tangible, sino en función del acontecimiento, del acto ético que se suma a otras acciones de otros sujetos y que dota de significación y valor (a nivel axiológico) a la comunicación que surge de tal diálogo. Deber ser, siempre en y a través de la presencia del otro, lo que conlleva una volición, es decir, una voluntad, y una acción, un acto ético. El acto tiene un autor, por tanto. Esta filosofía participativa implica atender los actos del ser no desde una perspectiva excluyente y específica, pero sí desde la totalidad del acto en conjunto. En este sentido, Bajtín diseñó el estudio de la constitución del ser, siempre en función del otro, de la alteridad.

Dedicó varios textos para comprender la producción del ser desde una dualidad interesante: el autor y el héroe, desde un sentido literal y abstracto, como se verá en el análisis de la película centro de este texto a partir de estas premisas. Tal dualidad se establece en términos de lo que José Alejos García, investigador del Centro de Estudios Mayas de la UNAM, denomina arquitectónica del mundo real, que se define por la fórmula: "yo para mí, yo para el otro, el otro para mí" (2004: 136). Por mi parte, añado también "el otro para sí", aspecto que cobra relevancia cuando se entiende la relación que establece el autor con su héroe y que estructura su propio "yo para mí" en contacto con el "yo para mí" del autor. 
El autor, como el otro del héroe, es capaz de describir las realidades extraestéticas. Yo no existo para mí en términos estéticos; me encuentro supeditado necesariamente al otro para poder completarme; en consecuencia, el héroe necesita del autor para ser completado. El otro se mantiene entre el yo y el mundo como eje articulador. Para Bajtín la verdad no es una conciencia, sino que se genera en el encuentro dialógico de varias conciencias. "La del autor, es conciencia de la conciencia, es decir, una conciencia que abarca a la conciencia del héroe y su mundo; que abraza y concluye la conciencia del héroe mediante los momentos que le son por principio extrapuestos ['transgredientes'] a ella misma, y que, al serle inmanentes, convertirían esa conciencia en falsa” (Bajtín, 2015: 24).

Dicho conocimiento del autor sobre los personajes y el contexto, lo mismo que la construcción de los actos éticos que ellos habrán de realizar permite que el autor pueda delinear la novela, la puesta en escena o, como en este caso, la película, en donde sus héroes habrán de desempeñarse. Esa cualidad que tiene el autor es gracias al excedente de visión que tiene, que en esencia tenemos todos sobre el otro. Es decir, uno se encuentra dentro de uno mismo, viviendo un lugar en el mundo, pero para comprenderlo, se requiere la visión de alguien más. Esa exotopía que condiciona el exceso de visión para con el otro se da a través de la cognición que construye un mundo de (aparente) validez universal y que la dota de la lógica establecida con antelación al diálogo que se establece entre autor y héroe (Bajtín, 2015: 25-26). "Debo experimentar intrínsecamente la vida de este otro hombre, ver axiológicamente su mundo desde el interior, del mismo modo como él mismo lo ve, ponerme en su lugar y luego, volviendo al mío propio, completar su horizonte con el excedente de la visión que se me abre desde mi lugar propio, pero ya fuera del otro" (Bajtín, 2015: 28-29).

Es necesario en este punto explicar que tal experiencia de la vida del otro no alude de ninguna manera a la empatía; sin embargo, se instala en la idea bajtiniana de "vivencia" que, según Bubnova, es la "participación afectiva y, por lo común, emotiva de un sujeto humano en una realidad ajena al sujeto" (nota 12 en Bajtín, 2015: 28). Por tanto, siguiendo este argumento, el autor ha de desarrollar su relación con el otro, en este caso el héroe, partiendo del conocimiento de ese "otro para sí”, es decir, del “yo para mí” del otro. Para ello será necesario un conocimiento profundo del otro, de su volición, de su marco axiológico y, por supuesto, de su cosmovisión.

\section{El iNDiO Y EL NACIONALISMO MEXICANO}

Cuando se aborda el estudio del nacionalismo se suele citar a dos pensadores fundamentales: Ernest Gellner y Anthony D. Smith. El primero ofrece una visión modernista de la formación de los nacionalismos, pues afirma que se genera a partir de la creación del Estado moderno producto de la Ilustración y que para constituirse echa mano de elementos de la propia cultura para constituir el nacionalismo de Estado (Gellner, 1991). En contraste con esta visión, Anthony D. Smith sostiene que el nacionalismo extiende con profundidad sus raíces en el devenir histórico del grupo en cuestión, de su expresión cultural, tradiciones, lengua. "La identidad nacional es esencialmente multidimensional; no se puede reducir a un sólo elemento, ni siquiera por parte de facciones concretas de nacionalistas, y tampoco puede ser imbuida fácilmente en una población utilizando métodos artificiales" (Smith, 1997: 13). Una identidad nacional que es aprovechada por un grupo, como menciona Smith, ha de establecer contenidos discursivos contrastantes. El llamado nacionalismo mexicano, ${ }^{[1]}$ como un proyecto del Estado nacional emanado de la Revolución mexicana, fue transmitido a la sociedad a través de múltiples vías y tal como menciona Natividad Gutiérrez Chong, investigadora de la UNAM que se especializa en temas de nacionalismo y su relación con las comunidades indígenas:

Por medio del sistema educativo y contiene una fuerte carga de simbolismo étnico; pero los grupos étnicos resisten la asimilación total mediante el hecho de sacar ventaja de las condiciones modernas. Un modelo evolucionista y determinista no puede explicar de manera satisfactoria la formación de la nación. Antes bien, el nacionalismo resulta impredecible en la medida en que se alimente de un sinnúmero de factores étnicos (2001: 50). 
En efecto, el factor étnico será un canal estupendo para establecer una dicotomía fundamental en nuestro nacionalismo: lo indígena prehispánico, prístino y puro frente a lo europeo, conquistador, agresivo, evangelizador. No obstante, en la práctica, se dio una suerte de adoración de lo europeo y de nostalgia de un pasado prehispánico ido. La misma Gutiérrez Chong (2015: 19) afirma, parafraseando a Fernando Benítez, que se privilegia la presencia del indio "muerto" (prehispánico) frente al indio "vivo" que es el contemporáneo y que se muestra como un obstáculo para el desarrollo del proyecto nacional.

Para la construcción de esta identidad nacional, colaboraron activamente muchos otros sectores y es de destacar el aporte de los artistas plásticos, como los firmantes del manifiesto socialista de la Escuela Mexicana de Pintura: los muralistas Diego Rivera, José Clemente Orozco y David Alfaro Siqueiros, los músicos como Silvestre Revueltas o Carlos Chávez y los escritores como Ermilo Abreu Gómez, Antonio Mediz Bolio o Mauricio Magdaleno. Por supuesto que lo hicieron motivados por iniciativa del Estado, pero es evidente que existía a su vez una necesidad de muchos de estos intelectuales por integrarse a la formación ideológica y plástica de México. José Vasconcelos daría los primeros pasos desde la recién creada Secretaría de Educación Pública en el gobierno obregonista para establecer una agenda encaminada a lograr el objetivo. Desde el poder, Vasconcelos diseñó estrategias para esa nueva "evangelización" nacionalista sustentada en la grandeza de México por su herencia y en un presente soportado en la "raza mestiza", lo que, a la larga, debilitaría la imagen de lo indígena y la colocaría en un nivel bastante precario frente a los demás integrantes de la nación. El indio, resulta ser un representante vivo de una de las raíces más importantes del nacionalismo, el ámbito indígena, pero concomitantemente, un clarísimo "obstáculo" para el progreso de la nación. Por tanto, no sólo había que llevarles la modernidad, sino que, a su vez, habría que castellanizarlos y dotarlos de los conocimientos que los hicieran partícipes del crecimiento de la nación. En su discurso para la inauguración del Congreso Indigenista Interamericano, Lázaro Cárdenas daría los elementos de la política indigenista que, todavía hasta fechas muy recientes, serían la tónica del accionar desde el poder ante las comunidades indígenas de nuestro país.

Lo que se debe sostener es la incorporación de la cultura universal al indio, es decir, el desarrollo pleno de todas las potencias y facultades naturales de la raza, el mejoramiento de sus condiciones de vida, agregando a sus recursos de subsistencia y de trabajo todos los implementos de la técnica, de la ciencia y del arte universales, pero siempre sobre la base de la personalidad racial y el respeto de su conciencia y de su identidad (Durán, 1972: 173).

Gutiérrez Chong (2001: 134-135) afirma que la política cardenista buscaba el reconocimiento de los pueblos indios, de su legado cultural y su eventual incorporación al Estado nación. No obstante, es necesario apuntar que se acentúa con este pensamiento esa dicotomía de civilización y barbarie en donde la construcción de la visión del otro, el indígena, queda adosada a la barbarie. Lepe-Carrión (2012: 64) afirma que la "idea de civilizar la barbarie, de integrar a las comunidades incivilizadas al proyecto de la Modernidad, es un concepto que atraviesa casi toda la historia de América y que desde la Colonia y la República (y hasta la actualidad) se ha venido instalando como una columna vertebral en las múltiples estrategias de poder que pretenden clasificar y definir los cánones de lo 'racional', de lo 'cultural' o de lo 'identitario'”. Federico Navarrete Linares, investigador del Instituto de Investigaciones Históricas de la UNAM, por su parte, sostiene que "la política indigenista permitiría culminar la construcción de las naciones indomestizas americanas como unidades orgánicas y raciales, libres de antagonismos culturales y resistencias a la aculturación" (2018: 32). Al analizar El Proceso de Aculturación (1957: 31 - 32), Gonzalo Aguirre Beltrán afirma que la versión del indígenismo que plantea es la contraparte ideológica de las políticas de miscegenación que se venían practicando desde el poder y que tendrían un sesgo evolucionista y señala:

El indigenismo es la expresión cultural de un fenómeno biológico, el mestizaje, el cual resulta inteligible sólo como producto de la emergencia y elevación del mestizo en el plano histórico. La teoría social que norma la acción política de los países latinoamericanos respecto al indio es lo que recibe la designación de indigenismo, pero la base orgánica de tal ideología está representada, 
no ciertamente por el indio, sino por el mestizo. Indigenismo y mestizaje son procesos polares que se complementan, al punto de tornarse imposible su existencia separada. El indigenismo requiere, como condición sine qua non de su ser, el substratum humano que le suministra el mestizaje. Éste, a su vez, requiere, para dar contenido y significación a la vida, el sistema axiológico que el indigenismo sólo puede proporcionarle. La interdependencia entre la base orgánica y la expresión cultural deviene indispensable (Aguirre Beltrán, 1957: 126-127).

Como se ve, la política indigenista del país vendrá en concordancia con la construcción del nacionalismo que buscará asimilar al indio al "progreso y al desarrollo" modernos y lo hará en la práctica desde esas políticas centradas en el Estado. A su vez, se apoyará en medios masivos, como el cine, la radio y la televisión para construir la imagen deseada. En la realidad, "Los indígenas fueron redefinidos como miembros de sociedades subdesarrolladas, confinadas a regiones de refugio ecológicamente marginales y sometidas a relaciones de sobreexplotación de las élites no indígenas regionales" (Navarrete Linares, 2018: 32).

\section{El iNDio EN EL CINE de la Época de ORO}

En el cine, la realidad descrita no tendría por qué ser diferente. La imagen del indio, como se ha comentado, ha sido representada de múltiples maneras, pero casi siempre en una dicotomía interesante: por un lado, en un entorno prehispánico, idílico, civilizado, orgulloso; por otro, como sucede con frecuencia en el cine nacional, en un entorno colonial o actual, fusionado con el campesino, vinculado a la pobreza y esencialmente conectado con el atraso y el subdesarrollo. Por supuesto, esta última contrasta con la primera y es común que sea utilizada a modo de crítica. En esta misma línea, primero en el cine y después en la televisión, la imagen del indio ha sido encaminada al desarrollo de un "personaje tipo" que integra en sí mismo la ignorancia, la inocencia, la suciedad y, con demasiada frecuencia, la estulticia. Por lo general, se le representa por comediantes que medran con la caricaturización del indio. En términos bajtinianos, es visible que el autor, en este caso cineastas al servicio del nacionalismo mexicano, desarrolla a su "héroe" desde su exotopía, pero sin acercarse a la auténtica vivencia de la que hemos hablado.

En efecto, hay historias que, en apariencia, buscan hacer homenaje a las comunidades indígenas y mostrar sus problemas, carencias y la agreste realidad en la que viven. No obstante, en algún momento terminan por mostrar el aspecto "incivilizado" de estos pueblos, lo que los lleva a ser engañados por el "civilizado y moderno" blanco o mestizo, repleto de vicios y que siempre busca obtener el beneficio propio a costa de los demás. Por supuesto, los indígenas que aparecen en estas cintas son ingenuos, castos de mente y acción, sumisos, bonachones y serviciales. Según Francisco de la Peña Martínez, investigador de la Escuela Nacional de Antropología e Historia (ENAH), lo anterior se da gracias a la imagen:

[...] elaborada desde la mirada de los mexicanos mestizos y criollos de clase media, desde los valores y prejuicios de la cultura occidental, y rara vez desde la perspectiva de los indígenas mismos. Imagen en la que el indio real es negado, silenciado o exotizado a través de múltiples estrategias narrativas, presentándolo como el reverso moral, positivo o negativo, de nosotros los occidentales, mostrándolo como un actor pasivo que se mueve impulsado por principios primarios y arcaicos, situándolo en un pasado indeterminado o en un mundo ahistórico, cerrado y dominado por el mito, la superstición, la violencia y el tradicionalismo (2014: 100).

A su vez, como apunta María del Rosario Vidal Bonifaz, investigadora de la Universidad de Gudalajara, el poder se valió del cine como una vía de transmisión del modelo de Nación y sus posibilidades:

[...] durante dicha etapa el gobierno encabezado por un líder carismático como Lázaro Cárdenas marcó la pauta para el eventual empleo del cine como un medio de propaganda acorde con los intereses del Estado que, surgido de la Revolución Mexicana, debió impulsar una serie de transformaciones que terminarían por dar forma al sistema político que, a pesar de todo, logró prevalecer durante varias décadas, hecho que se tradujo en un clima de relativa calma, suficiente para permitir avances y logros en diversas áreas de la vida nacional (2011: 49). 
Por tanto, la figura del indio, igual que otros “tipos” en el cine, debía estar en concordancia con la construcción de ese Estado nacional y, si no, debía ser desarticulado desde el discurso mismo. Por ejemplo, De la Peña Martínez afirma que en varias cintas, como Maria Candelaria (1944) o en Janitzio (1935), la trama exhibe la "cerrazón” y la "barbarie" de las comunidades indígenas al lapidar en ambas a sus protagonistas femeninas por haber trascendido "normas" establecidas por la comunidad: en la primera por supuestamente posar desnuda frente a un pintor a todas luces mestizo y moderno y, en la segunda, por haberse "entregado" a un fuereño (2014: 98-107).

La supuesta costumbre indígena del ajusticiamiento público a causa del establecimiento de relaciones sexuales con los extranjeros es una invención deliberada de los realizadores de este film, que no tiene ninguna base histórica, pero funciona como un motivo dramático que opera eficazmente en la trama. En cualquier caso, tanto la historia de Tribu como la de Janitzio, aunque situadas en épocas distintas, comparten un mismo motivo, a saber, las consecuencias negativas que acarrean las relaciones entre indígenas y no indígenas o entre lugareños y fuereños, un lugar común cinematográfico que, falsa y denigrantemente representa al mundo indígena como cerrado, endogámico y hostil, que convierte en tabú las relaciones con el otro extranjero (De la Peña Martínez, 2014: 102).

En la Época de Oro del cine nacional (1935 a 1956), según Castro-Ricalde (2014), se contribuye en gran manera a la colonización del imaginario social pues se establece una relación de dominador-dominado a través de la proyección de personajes y situaciones que se convierten en el significado de lo "mexicano". Como afirma Juan Pablo Silva Escobar, "así, las películas de la Época de Oro naturalizan en la pantalla aquello que debe ser entendido como la esencia de la 'mexicanidad' y, con esa naturalización, instalan en el imaginario social la ideología del multiculturalismo restringido" (Silva, 2011: 12). Por supuesto, en el establecimiento de dicha colonización, la presencia del indio queda perfectamente delineada, ya que con frecuencia serán la servidumbre y los sujetos (mudos o borrosos, indistinguibles) del expolio y el abuso de los poderosos, en especial de hacendados, caporales y políticos, muchos de ellos, anteriores a la Revolución, apoyados en el porfiriato al que hay que renunciar. "Más que mostrar el modo de hablar, de ser o de vestir de los miembros de una comunidad étnica específica, la mayoría de los filmes indigenistas de esta época se caracterizan por construir un modelo abstracto del indígena, un compuesto que amalgama de manera arbitraria rasgos culturales de diferentes etnias en un mismo personaje" (De la Peña Martínez, 2014: 108).

En este mismo tenor, los indígenas no sólo no tienen voz en la construcción de sus propios personajes, sino que a su vez no tienen siquiera presencia, no los pueden interpretar. En la gran mayoría de estas cintas no existen actores indígenas, no al menos en los roles protagónicos. Acaso aparecen como extras, en la muchedumbre de algún rancho, como peones o como cargadores, pero nunca frente a la cámara interpretándose a sí mismos. Por ejemplo, en la cinta María Candelaria (1944), de Emilio el Indio Fernández, la protagonista es Dolores del Río, que de indígena no tiene nada, al igual que su coprotagonista Pedro Armendáriz, quien interpreta a Lorenzo Rafael. Lo peor del caso es que tampoco parecen serlo y, salvo el maquillaje con el que los "embetunaron" para hacerlos lucir más morenos y colocarles un vestuario indígena, ni el director ni la producción hicieron algo más para hacerlos parecer como tal. Pensaron, al parecer, que el sonsonete con el que hablan ambos personajes, otro estereotipo, era más que suficiente. "En este sentido, el Estado mexicano se ha reservado el derecho a definir lo legítimamente indígena, imponiendo sus criterios acerca de lo que es valioso y recuperable y lo que es desechable o condenable en el modo de vida de éstos" (De la Peña Martínez, 2014: 103). Es una sucesión constante de dualidades que visten el discurso de odio-amor en que lo indígena es ceñido y negado por el nacionalismo y por la sociedad que es colonizada y que, a la fuerza de años y años de expresión mediática y de acciones concretas en las poblaciones rurales donde lo colonial todavía hoy pervive, estructuran y confirman la dicotomía civilización-barbarie, es decir, el nosotros y el otro, en una alteridad en la que el indígena siempre lleva las de perder.

Como lo afirma Julia Tuñón, investigadora emérita del Instituto Nacional de Antropología e Historia (INAH): 
Lo nuestro entonces, son las costumbres, el pasado y los paisajes. Se busca una construcción de nación que homogenice las diferencias, que ponga el acento en lo común, y eso ineludiblemente provoca una mixtificación. Se trata de crear un territorio propio, y para hacerlo se construye un estereotipo, pero con él se pretende acceder a lo universal, dar al cine internacionalidad y desarrollo lógico según nuestra idiosincracia'. Se quiere construir un modo universal de ser mexicano (2010: 85).

En esa construcción, el indígena juega un rol, pero no uno protagónico.

\section{Chilam BaLAM, La Película}

Para Emilio García Riera y Fernando Macotela en La guía del cine mexicano (1994: 21), este "melodrama histórico incluyó locaciones yucatecas (sobre todo en Chichén Itzá) bien fotografiadas en colores por Alex Phillips para contar una historia de la conquista, con enfrentamientos armados entre españoles e indígenas. Lástima que la dirección corriera a cargo del inhábil debutante De Martino". En esa sencilla ficha, se encuentran elementos interesantes. Al respecto, los autores enfatizan la virtud de la producción al filmar la cinta en Yucatán, en específico en Chichén Itzá, lo cual es loable, pero a la vez se critica la novatez del director. No obstante, en realidad la atención no está centrada en los atributos o falencias de la producción, dirección o actuación, sino en el discurso de la cinta y su elaboración en los términos señalados: exotopía, autor-héroe y alteridad.

El personaje central de la película es una suerte de astrónomo-profeta y especialista ritual de nombre Chilam Balam, interpretado por Carlos López Moctezuma (Ciudad de México, 1909-Aguascalientes, 1980), quien vaticina la llegada de los europeos. Mercedes de la Garza, en su prólogo a Chilam Balam de Chumayel (2006), citando a su vez al Libro de los libros del Chilam Balam (2005), afirma que:

Chilam Balam fue un taumaturgo concreto, un sacerdote del pueblo de Maní que parece haber vivido poco antes de la Conquista y que tenía gran reputación como profeta. Al lado de otros sacerdotes, llamados Napuctun, Ah Kauil Chel, Nahau Pech y Natzin Yubun Chan, predijo la llegada de una nueva religión, por lo que después de la Conquista su profecía se interpretó como un aviso de la llegada de los españoles y el cristianismo" (2006, p. 12).

La palabra Chilam significa "el que es boca", es decir, quien profetiza y era el nombre que se le otorgaba a quienes interpretaban los textos escritos (códices); por su parte, Balam significa “jaguar o brujo” (De la Garza, 2006: 12). En la tradición escrita maya colonial de la península de Yucatán, existen numerosos libros denominados Chilam Balam. Algunos de los que se conocen en la actualidad son el de Chumayel, el de Tizimín, el de Maní, el de Ixil, entre otros. Su contenido no es uniforme, pues incluyen en su interior textos proféticos, calendáricos, históricos, medicinales, esotéricos y varían de modo considerable de uno a otro.

Para los pueblos mayas prehispánicos y coloniales, cuyo pensamiento se sustentaba en la concepción cíclica del tiempo, las profecías eran un tema fundamental, no sólo para comprender el devenir histórico del tiempo, sino para entender la carga y el sentido que habría de tener tal o cual tiempo que regresaba y cómo deberían vivirlo. [2] Tan real era esta concepción que muchas rebeliones indígenas coloniales se sustentaron en la idea de la profecía que se cumplía, como vemos en la rebelión de Jacinto Canek de 1761, abordada a profundidad en Bracamonte y Sosa $(2004,2001)$ o en León O’Farrill (2018).

Es preciso contrastar la versión histórica o registrada en textos coloniales mayas como los chilames y la concepción de profecía con lo que se muestra en la cinta de De Martino, ya que, muy independiente de las claras inconsistencias que habrá, el sentido de la elaboración de la película será otro en su totalidad. De hecho, conserva mucho de lo que se ha mencionado de otras producciones de corte indigenista: un reparto enteramente mestizo sin la presencia de indígenas, el acomodo de la historia para ser comprendida por un público occidental y hablada por completo en español. La sinopsis que viene en el estuche de la película no podría ser más evidente en este sentido: "Esta es una epopeya histórica que nos lleva hasta principios del siglo XVI, cuando los mayas estaban en plena decadencia y habían sido vencidos por los conquistadores españoles. En esta historia, Naya, hija de Chilam 
Balam (adivino de la comunidad) decide unir su destino al del hijo del español Montejo. De esta forma, el director Ínigo de Martino, nos ofrece su versión del nacimiento de una nueva raza”.

Con la supuesta decadencia de las comunidades mayas que están a punto de ser conquistadas, pues perdieron su unidad, se pretende justificar no sólo la conquista en un sentido tecnológico, sino por su debilidad, su decadencia, con instituciones y tradiciones caducas, "primitivas", y vendrá su caída a manos de una "civilización" cuyos valores han de ser "superiores". En la introducción de la cinta, es notorio este argumento narrado en voz en off:

Proyectándose hacia el Golfo de México se encuentra la Península de Yucatán donde, por más de 12 siglos, floreció la más brillante civilización del Nuevo Mundo, la de los pueblos mayas. Sus conocimientos matemáticos y astronómicos fueron extraordinarios, pero en lo que mayormente destacaron, fue como escultores y arquitectos. Como todos los grandes pueblos, un díaperdieron su unidad y el Imperio se derrumbó y en los albores del siglo XVI, poco antes de la llegada de los españoles, del antiguo esplendor y poderío de los mayas, sólo quedaba el recuerdo. Los habitantes de Chichén Itzá, una entre las tantas tribus de los mayas, sólo conservaban de sus antepasados las costumbres y los ritos. Su limpio cielo azul les inspiró el color sagrado de los sacrificios en que, como en todas las civilizaciones primitivas, ofrendaban a la divinidad sus propias vidas. Y así, en 1508, clamaban a sus dioses para que cesaran las calamidades que azolaban a su pueblo (De Martino, 1955).[3]

Destacan los conceptos Nuevo Mundo, unidad del Imperio maya, civilización primitiva, claves para comprender el sentido en el que se elabora la cinta. Antes que nada, se instala en el pensamiento occidental que determina que Europa es el Viejo Mundo y América el Nuevo, como si no hubieran existido ambos territorios en el mismo tiempo y con civilizaciones paralelas. En este orden de ideas, América es un territorio "virgen" en cuanto al pensamiento europeo y su "larga" trayectoria de civilización. Resulta curioso, empero, que los conquistadores - salvo el Montejo, joven interpretado por Carlos Baena, y quien termina emparejado con Naya- son ambiciosos y agresivos, características con las que se ha pintado a los conquistadores. Tanto para el guionista como para el director, ambos autores en el sentido bajtiniano del término, no hay nada que discutir en este sentido. De hecho, lo confirma la idea de caracterizar al Imperio maya como una civilización primitiva, porque tiene la costumbre del sacrificio humano, y a los conquistadores bien uniformados y debidamente armados, como un ejército regular. Vale aclarar en este punto que jamás existió algo que pudiera ser considerado como "imperio" [4] en territorio mesoamericano y desde el Preclásico se observa la convivencia de numerosos centros de poder que hacían alianzas diversas con otras poblaciones y de las que recibían tributos diversos. No existió un poder panmesoamericano centralizado en la figura de un gobernante específico, lo que pudiera ser caracterizado en Europa como un rey o emperador. Los grupos de este periodo de contacto con los europeos vivían una recomposición en múltiples aspectos tanto en lo político como también en lo social.

Durante la primera mitad del siglo XVI existían en Yucatán, al menos, 19 capitales. Desde estos puntos, los halach uini$c o o b$, o grandes señores, gobernaban un conjunto variable de poblaciones que los mayas llamaban cuchcabal y los españoles provincia. La caída de Mayapán inauguró una etapa de incertidumbre política, situación que propició que un sinnúmero de bataboob, o caciques, con sus respectivos pueblos, permanecieran independientes de las capitales indígenas (Quezada, 2011: 22-23).

Se puede caracterizar al periodo de incertidumbre política, justamente como lo hace Quezada, uno en donde los denominados halach uinicoob (hombres verdaderos) pugnaban entre sí para consolidar su posición frente a los demás. En todo caso, dicha circunstancia será aprovechada por los conquistadores para establecer el dominio colonial en la región. Tal circunstancia fue resuelta por los autores de la película al denominar en "declive" a esa sociedad.

En la cinta, de acuerdo con la introducción en voz en off, la decadencia vendría acompañada de ceremonias a sus deidades, en especial a Itzamna', deidad suprema y creadora del panteón maya en la zona ceremonial de Chichén Itzá -ya abandonada para la época en que se ubica la acción-, que culminan en el sacrificio donde se extrae el corazón de un hombre. De igual manera en el cenote sagrado de la misma ciudad mediante el 
sacrificio de mujeres que eran arrojadas a su interior con peso amarrado a sus pies. Una sociedad en decadencia y primitiva, siguiendo el argumento de la película, habrá de recurrir al sacrificio humano. Nuevamente, es visible la oposición yo/otro, civilización/barbarie de la que se ha hablado.

La manera de construir el guion viene determinada por una visión necesariamente exotópica, pero sin la profundidad que propone Bajtín, de los autores respecto no sólo a lo indígena en general, sino también a la historia de los mayas. Lo más probable es que ello se deba a que el conocimiento que los autores tuvieron de la historia de los mayas peninsulares haya sido muy limitado e interpretado en función de paquetes narrativos establecidos desde su formación occidental y que, para mediados del siglo XX serían lugar común, como el pensamiento profético de los mayas (con una visión bíblica catastrofista) o la creencia en una deidad suprema. Incluso, desde su propia visión de lo que implica la civilización, la barbarie y, por consiguiente, una sociedad primitiva y decadente. Sin duda, el autor está construyendo la historia desde su "yo para mí” con una clara predisposición hacia el "otro para mí". Hay que decir que es evidente que el objetivo de los autores, más que escribir una trama con exactitud histórica, es hacer llegar a un público mexicano, con un pensamiento occidental, una narración que explique el drama de la Conquista y sus consecuencias en la constitución de la nación mexicana mestiza de sangre y de pensamiento. Esta misma constante habrá de afectar a la factura de los personajes. La cinta culmina con estas líneas que corroboran nuestra postura. "La profecía de Chilam Balam se cumplió. Su pueblo cayó en pleno ocaso. Y de la sangre de esas dos razas nació una nueva, joven y vigorosa” (De Martino, 1955). El mestizaje, como la culminación del proceso de aculturación de la que hablaba Aguirre Beltrán.

Siguiendo este argumento, no es de extrañar que no haya indígenas en el reparto y al igual que en otras cintas mencionadas, se contrató a actores con una trayectoria fílmica más o menos conocida con el objetivo claro de conseguir ganancias en las taquillas, pero también porque no se contaba con una élite de actores indígenas prestos para aparecer en cualquier película; mucho menos cabe la posibilidad de pensar en academias o instituciones para su formación actoral. Y, aunque ambas situaciones existieran, como lo he dicho, no se trataba de representar la realidad, sino de la elaboración de un discurso nacionalista sobre el mestizaje aprovechando el tema indígena sin que hubiera la necesidad de representarlo a cabalidad. Cabe preguntarse siquiera si se lo hubieran cuestionado. Esto mismo se extiende a la lengua, pues todas las cintas de corte indigenista que conozco de la época están habladas en español. Y si no se contaba con actores que dieran más o menos el "perfil” indígena, en específico por el color de piel, pues para eso existía el maquillaje. Carlos López Moctezuma (Chilam Balam) es muy difícil que pasara por indígena, lo mismo que Lucy González (Naya, hija de Chilam Balam), por lo que sólo fueron maquillados para oscurecer su piel.

De hecho, la contratación de González en la cinta parece responder a la necesidad de mostrar un tipo de belleza que, pese al discurso nacionalista, seguía siendo aceptado a la perfección en las cintas del periodo: una mujer con rasgos claramente europeos, si no rubia, al menos castaña o de pelo oscuro, pero tez clara o apiñonada. Ejemplos de lo anterior son Dolores del Río en María Candelaria (1944) o María Félix en Maclovia (1948). Algo parecido sucede con los varones, pues varios actores mestizos, o incluso de tez clara, serán sometidos al maquillaje. El actor más representativo es Pedro Armendáriz, quien hará de indígena en numerosas cintas como Maria Candelaria (1944), Maclovia (1948) o La Rebelión de los Colgados (1954); también puede verse a Ignacio López Tarso en Chilam Balam (1955) y en Macario (1960). El objetivo será personificar un imaginario indígena que no lo implique del todo, es decir, que no lo represente.

A su vez, los personajes serán trabajados en función del discurso propio de los autores, es decir, de la multiplicidad de discursos que los constituyen como occidentales, nunca en realidad a partir del discurso del otro (el maya) y de la multiplicidad de discursos que lo constituyen a su vez. La concepción de "el otro para mí" viene, en este caso, compuesta enteramente desde "el yo para mí" y desde ahí se proyecta el diseño del personaje, sus diálogos, sus valores y sus acciones. Por ejemplo, en las escenas iniciales, no se ve a un especialista ritual conduciendo una ceremonia de adoración a una deidad del panteón prehispánico; es evidente, en cambio, visualizar a un actor no indígena que dirige un rezo, no indígena también, a una deidad desprovista de lo indígena a la que el supuesto 
"sacerdote" le suplica: "Itzamna', danos la paz". De igual manera, el deseo por sobrevivir de Naya y su necesidad de encontrar al amor de su vida están elaborados para una mujer mexicana de mediados del siglo XX que no está de acuerdo con ser sacrificada sin conocer y vivir el amor. En este mismo sentido, la debilidad de Chilam Balam es la de un padre que entiende que su única hija debe ser feliz, cueste lo que cueste; si para que ello suceda, tiene que transgredir el equilibrio brindado por el sacrificio, en perjuicio del pueblo en su conjunto, eso será lo de menos: lo individual sobre lo colectivo. El autor da vida a "héroes" comprensibles en su línea temporal, lógica y moral y dialoga con un público occidental igual que él mismo. El cineasta, como en una especie de metarrelato es, a su vez, el héroe de algún otro "autor" no importa si es producido por la sociedad o por el Estado y responde al discurso de alguien más, vive su propio personaje junto con otros intelectuales contemporáneos. No se explora a profundidad el ámbito de lo maya; en cambio, apenas se dan unas pinceladas para lograr delinear personajes y el tema, ubicar desde el estereotipo a un público receptivo a ese tipo de discursos que se ha visto influenciado desde su infancia por la educación oficial. Por ello, no es necesario que exista exactitud, y mucho menos indígenas reales en la cinta. Al contrario, eso quizá marcaría en verdad una diferencia tan insondable que haría que el proyecto fracasara estrepitosamente. En pocas palabras, los autores de la película no "vivencian” al indígena como lo establece Bajtín. De lo que se trata es de representar la "vivencia" de personajes occidentales: el amor y el desamor, la ilusión y la desesperanza, la relación del hombre con Dios y la religión, la oposición libertad-opresión, conceptos tan republicanos y democráticos, pero que nada tienen que ver con comunidades mayas del siglo XVI en la península de Yucatán, no importa si Chichén Itzá sea utilizada como locación central. La debacle de la sociedad maya es positiva a final de cuentas pues es lo que nos legó una patria y lo que nos lleva a ser una nación moderna libre de "falsas" deidades y de prácticas "salvajes" como el sacrificio humano.

La gran triunfadora debe ser la patria representada en este caso por el mestizaje. La película culmina con unas líneas pronunciadas por un Chilam Balam moribundo para después mostrar la imagen de un altar maya con una cruz encima y las manos entrelazadas de Naya y el mozo Montejo.

Toca a su fin la vida de nuestros pueblos. He visto en las estrellas que vendrán hombres blancos y barbados por el mar de oriente y su sangre se mezclará con la nuestra. Primero en el suelo por el odio, luego en los cuerpos por el amor. Y nacerá otro pueblo que ni será el de ellos, ni el de nosotros. Y traerán un madero enhiesto cruzado con otro, de gran virtud contra los demonios, que arrojará de los templos a todos nuestros dioses [...] lo he visto. Todo se acabará para que todo empiece [...] (De Martino, 1955).

La identidad nacional, reforzada por el cine, queda trágicamente colonizada por discursos que se debaten entre una adoración/odio a la civilización traída por Europa y una fascinación/asco por esa herencia indígena que se manifiesta en la piel y las costumbres de los habitantes de la nación.

\section{Consideraciones finales}

De acuerdo con lo expuesto en este artículo, convergen numerosos elementos para establecer que el cine de corte indigenista colaboró en la construcción de lo que entendemos por el nacionalismo mexicano junto con otras expresiones como la literatura, la pintura, la escultura y el teatro. Sin embargo, el poder mismo de la imagen en movimiento y del sonido, dota al cine de una superioridad discursiva que penetró hondo en las conciencias de los habitantes de la nación mexicana que estaba apenas esbozándose. La identidad nacional queda supeditada a la idea del otro, siempre atendiendo a la visión del "yo para mí" y prácticamente nunca del "otro para mí" o del "otro para sí mismo". Chilam Balam de De Martino es, pues, una demostración del cine de corte indigenista como medio para la transmisión de discursos de identidad nacional sustentados en el mestizaje, en el rechazo a lo indígena y en una relación ambigua con lo europeo.

Sea que aparezcan en una película, en un programa televisivo, en una consulta para la construcción de un megaproyecto del pasado o del presente, las comunidades indígenas siempre serán ese paréntesis curioso en nuestra 
historia, esos personajes que son llamados a escena cuando se trata de justificar construcciones identitarias o discursos políticos de cualquier denominación partidista o corriente ideológica, pero que con frecuencia serán olvidados por el sistema. Como se ve en este trabajo, el drama de estos pueblos es siempre ser testigos de una vida que nunca han llevado, de un rol que no sólo les es extraño, sino que tampoco pueden desempeñar, y del torpedeo constante a la construcción de su propia identidad en la comprensión de su "yo para mí".

\section{AnÁlisis PROSPECTIVo}

A partir de este artículo, se busca incentivar el estudio del aprovechamiento de la imagen de lo indígena en la historia de nuestro país tanto en el cine como en la televisión con el fin de contribuir a visibilizar el racismo y la discriminación que hoy día existen de manera regular en todos los espacios de nuestra vida cotidiana. La expresión "indio" en su forma más despectiva, de acuerdo con lo expuesto, es sinónimo de "corriente", "vulgar", "ignorante", "pobre" o "subdesarrollado" y es común que sea utilizada para justificar estancamiento o retroceso. En la televisión, en este sentido, la imagen ha sido empleada desde los inicios de la industria, lo que a la larga ha generado una visión del otro en extremo estereotipada, aspecto que han aprovechado comediantes para construir carreras y normalizar, desde la risa, el racismo persistente. Ejemplos sobran: Madaleno de Francisco Fuentes, que participó muchos años en el programa El Club del Hogar transmitido de 1951 a 1984, primero con Daniel Pérez Arcaraz y luego con Paco Stanley, Maclovio de Luis de Alba, Chano y Chón de Eduardo Manzano y Enrique Cuenca, los Polivoces, más recientemente el Indio Brayan de Hugo Alcántara o la India Yuridia de Perla Yuridia Ruiz Castro o la retransmisión constante de las películas de la India María (María Elena Velasco). De hecho, ahora cualquiera puede encontrar sus videos en YouTube. Las caracterizaciones son prácticamente iguales que en el cine: problemas al hablar el español -que no es su lengua materna-, vestimenta típica de la supuesta región de la que provienen, pero que tiende a ser estereotipada en su totalidad y con actitudes y comportamientos absurdos, bastos, salvajes, frente al otro, al moderno, citadino y "civilizado". Tras años y años del refuerzo de esta imagen a través de los medios y de la vida cotidiana, hoy en pleno siglo XXI, pervive esa visión negativa del otro. El caso más reciente fue el de Yalitza Aparicio, actriz principal en la película Roma (2018) del director Alfonso Cuarón quien, que al ser nominada al Óscar a la mejor actriz por la Academia de las Artes y las Ciencias Cinematográficas de Hollywood, recibió una andanada de críticas sumamente racistas y clasistas tanto del público como de colegas del ámbito de la actuación y del cine. Por tanto, es necesario profundizar en este fenómeno en todas sus vertientes audiovisuales (cine, televisión, redes) para evidenciarlo, criticarlo y, a su vez, incidir en su discusión pública y a que poco a poco se vayan eliminando estos discursos en las producciones audiovisuales en México. De igual manera, es posible hacerlo desde la óptica del dialogismo bajtiniano que nos permite comprender al otro desde la arquitectónica del ser, que ya he expuesto, con lo que nuestras relaciones con los otros puedan establecerse en una horizontalidad más pertinente con el mundo que deseamos.

\section{Agradecimiento}

Agradezco enormemente a las y los dictaminadores de este trabajo por su invaluable apoyo para la mejora de su estructura y contenido.

\section{ReFERENCIAS}

Aguirre Beltrán, G. (1957). El proceso de aculturación. México: UNAM. Alberro, S. (1999). Eláguila y la cruz, orígenes religiosos de la conciencia criolla. México siglos XVIy XVII. México: COLMEX, FCE. 
Alejos García, J. (2004). Hablar del otro en mitología maya, en H. Beristáin y G. Ramírez Vidal (coord.). La Palabra florida. La tradición retórica indigena y novohispana (pp.135-146.) México: UNAM.

Bajtín, M. M. (2015). Yo también soy (Fragmentos sobre el otro). T. Bubnova (trad.) Buenos Aires: Ediciones Godot. Barrera Vázquez, A. y Rendón, S. (2005). El libro de los libros de Chilam Balam (seg. ed.). México: FCE.

Bracamonte y Sosa, P. (2010). Tiempo cíclico y vaticinios. Ensayo etnohistórico sobre el pensamiento maya. México: Porrúa

Bracamonte y Sosa, P. (2004). La encarnación de la profecía, Canek en Cisteil. México: Instituto de Cultura de Yucatán, CIESAS.

Bracamonte y Sosa, P. (2001). La conquista inconclusa de Yucatán. Los mayas de la montaña, 1560-1680. México: CIESAS, Porrúa.

Brading, D. (2004a). Los orígenes del nacionalismo mexicano. México: ERA

Brading, D. (2004b). Mito y profecía en la historia de México. México: CFE.

Castro-Ricalde, M. (2017). El cine mexicano de la Edad de Oro y su impacto internacional. La Colmena, 82 (abril-junio), 9-16. Disponible en https://lacolmena.uaemex.mx/article/view/5371.

De la Peña Martínez, F. (2014). Por un análisis antropológico del cine. Imaginarios fílmicos, cultura y subjetividad. México: Ediciones Navarra.

Durán, L. (comp.) (1972). Lázaro Cárdenas. Ideario Político. México: Era.

Florescano, E. (2005). Imágenes de la patria a través de los siglos. México: Taurus.

Florescano, E. (2003). Etnia, Estado y Nación. México: Taurus.

García Riera, E. y Macotela, F. (1994). La guía del cine mexicano. México: Patria.

Gellner, E. (1991). Naciones y Nacionalismo. México: Alianza Editorial.

Gutiérrez Chong, N. (2015). El indigenismo del PAN y el festejo del bicentenario del Estado Mexicano). México: UNAM, Instituto de Investigaciones Sociales/Bonilla Artigas Editores. Disponible en http://ru.iis.sociales. unam.mx/jspui/bitstream/IIS/5209/1/indigenismo\%20PAN.pdf

Gutiérrez Chong, N. (2001). Mitos nacionalistas e identidades étnicas. Los intelectuales indígenas ante el Estado Mexicano. México: Conaculta.

Lafaye, J. (2002). Quetzalcóatl y Guadalupe, la formación de la conciencia nacional. México: FCE.

León O’Farrill, I. (2018). ;Se han sublevado los indios! Canek, cambios y continuidades de un símbolo maya. México: Juan Pablos Editor/BUAP.

Lepe-Carrión, P. (2012). Civilización y barbarie. La instauración de la "diferencia colonial" durante los debates del siglo XVI y su encubrimiento como "diferencia cultural”. Andamios, 9(20),63-88. https://doi. org/10.29092/uacm.v9i20.371

Mediz Bolio, A. (trad.) (2006). Chilam Balam de Chumayel (seg. ed.). M. De la Garza (pról.). México: Conaculta.

Navarrete Linares, F. (2018). Hacia otra historia de América. Nuevas miradas sobre el cambio cultural y las relaciones interétnicas. México: UNAM. Disponible en http://www.historicas.unam.mx/publicaciones/publicadigital/libros/otrahistoria/america.html

Navarrete Linares, F. (2004). ¿Dónde queda el Pasado? Reflexiones sobre los cronotopos históricos, en V. Guedea (coord.). El Historiador frente a la Historia. El tiempo en Mesoamérica (pp. 29-52). México: UNAM.

Navarrete Linares, F. (1996). La vida cotidiana en tiempos de los mayas. México: Planeta.

De Martino, Í. (director). (1955). Chilam Balam [película]. [DVD]. A. Orive Alba (prod.). México: Clasa Films Mundiales. 
Quezada, S. (2011). La colonización de los mayas peninsulares. México: Gobierno de Yucatán.

Silva Escobar, J. P. (2011). La Época de Oro del cine mexicano: la colonización de un imaginario social. Culturales. 7(13), 7-30. Disponible en http://culturales.uabc.mx/index.php/Culturales/article/view/357

Smith, A. D. (1997). La identidad nacional. Madrid: Trama Editorial.

Tuñón, J. (2010). Tu mirada me descubre: el “otro" y la reafirmación nacionalista en el cine mexicano. En torno al premio a María Candelaria (Fernández, 1943), en Cannes. Historias, 74, 81-98. Disponible en https:// www.estudioshistoricos.inah.gob.mx/revistaHistorias/wp-content/uploads/historias_74_81-98.pdf

Vargas Pacheco, E. (2004). Tiempo y espacio sagrados entre los mayas. El Katún 8 ahau: patrón cíclico, en Guedea, V. (coord.), El Historiador frente a la Historia, El tiempo en Mesoamérica (pp. 195-231). México: UNAM.

Vidal Bonifaz, M. del R. (2011). Racionalidad burocrática y dominación carismática: el cine mexicano como estrategia del Estado Nacional en México. Revista del Centro de Investigación de la Universidad la Salle. 9(35). Disponible en http://revistasinvestigacion.lasalle.mx/index.php/recein/article/view/147

Vizcaíno, F. (2004). El nacionalismo mexicano, en los tiempos de la globalización y el multiculturalismo. México: UNAM.

\section{Notas}

[1] Sobre la formación de la identidad nacional y el nacionalismo en México recomiendo los estudios de Fernando Vizcaíno (2004), Natividad Gutiérrez Chong (2001), David Brading (2004a y 2004b), Solange Alberro (1999), Jacques Lafaye (2002) y Enrique Florescano (2005 y 2003).

[2] Para profundizar sobre el particular hay una extensa bibliografía. Sugiero Bracamonte y Sosa (2010, 2004, 2001), Navarrete Linares (2004), Vargas Pacheco (2004).

[3] Las cursivas son mías.

[4] No es posible en este espacio abundar en este concepto en particular. Comparto, empero, esta cita de Federico Navarrete Linares a cuento de lo que afirmo: "Los diferentes pueblos mayas nunca constituyeron una unidad política: ninguna ciudad o estado maya ha sido capaz de unificar a todos los hablantes de lenguas mayenses. Esta diversidad política fue resultado y causa, a la vez, de una gran diversidad cultural, acentuada también por los diferentes medios geográficos en que se han desenvuelto los pueblos mayas y sus distintas relaciones con los demás pueblos de Mesoamérica y de la América moderna” (1996: 13).

\section{BY-NC-ND}

